\title{
Composite Bonding to Stainless Steel Crowns Using a New Universal Bonding and Single-Bottle Systems
}

\author{
Mohammad Ali Hattan, ${ }^{1}$ Sharat Chandra Pani, ${ }^{1}$ and Mohammad AlOmari ${ }^{2}$ \\ ${ }^{1}$ Division of Pediatric and Preventive Dentistry, Riyadh Colleges of Dentistry and Pharmacy, P.O. Box 84891, \\ Riyadh 11681, Saudi Arabia \\ ${ }^{2}$ Division of Restorative Dentistry, Riyadh Colleges of Dentistry and Pharmacy, P.O. Box 84891, Riyadh 11681, Saudi Arabia
}

Correspondence should be addressed to Sharat Chandra Pani; sharatpani@hotmail.com

Received 7 January 2013; Accepted 13 March 2013

Academic Editor: Francesco Carinci

Copyright (C) 2013 Mohammad Ali Hattan et al. This is an open access article distributed under the Creative Commons Attribution License, which permits unrestricted use, distribution, and reproduction in any medium, provided the original work is properly cited.

\begin{abstract}
Aim. The aim of this study is to evaluate the shear bond strength of nanocomposite to stainless steel crowns using a new universal bonding system. Material and Methods. Eighty (80) stainless steel crowns (SSCs) were divided into four groups (20 each). Packable nanocomposite was bonded to the lingual surface of the crowns in the following methods: Group A without adhesive (control group), Group B using a new universal adhesive system (Scotchbond Universal Adhesive, 3M ESPE, Seefeld, Germany), and Group $\mathrm{C}$ and Group D using two different brands of single-bottle adhesive systems. Shear bond strengths were calculated and the types of failure also were recorded. Results. The shear strength of Group B was significantly greater than that of other groups. No significant differences were found between the shear bond strengths of Groups $\mathrm{C}$ and $\mathrm{D}$. The control group had significantly lower shear bond strength $(P<0.05)$ to composite than the groups that utilized bonding agents. Conclusion. Composites bonding to stainless steel crowns using the new universal bonding agent (Scotchbond Universal Adhesive, 3M ESPE, Seefeld, Germany) show significantly greater shear bond strengths and fewer adhesive failures when compared to traditional single-bottle systems.
\end{abstract}

\section{Introduction}

Stainless steel crowns (SSCs) are most commonly used for full coverage restoration of posterior primary teeth [1-3]. Given the nature of primary enamel, the need for a full coverage restoration in children is all the more important [4]. For children who presented with large, multisurface carious lesions of the primary teeth, the American Academy of Pediatric Dentistry recommended the full coverage of crowns using SSCs [5]. Despite their high success rate, this proven restoration often fails to meet the esthetic demands of patients and their parents $[3,6]$.

Esthetic SSCs are composite or porcelain coatings that are chemically or mechanically attached to a metal coping which allows for a tradeoff between their respective strengths and weaknesses [6]. Esthetic SSCs have several shortcomings relative to traditional SSC restorations such as requiring a greater reduction of tooth structure during preparation [7], inability to crimp the crown [8], and repair of fractured coatings sometimes requiring complete replacement [9]. The shape of an esthetic SSC cannot be altered, because this would change the rigid metal coping structure beneath the somewhat brittle composite, leading to the possibility of future fracture of the composite [10]. Although there is documentation of the repair of fractured esthetic crowns [11], replacement of the crown is often the only method of managing such failures [9].

A treatment modality that allows for contouring of the crown as well as adequate retention is the chair-side veneering of composite to stainless steel crowns [12]. The use of such crowns has been restricted by the poor esthetics of the metal display due to inadequate bonding of the metal to composite [13].

Recently, a dental adhesive has been developed for multipurpose bonding (Scotchbond Universal, 3M-ESPE, Seefeld, Germany). This adhesive, developed for repairs in 
prosthodontic crowns, utilizes self-etch phosphorylated methacrylates that are believed to result in more efficacious bonding to metal as well as tooth structure $[14,15]$. However, to the researchers knowledge this system has not been tested on stainless steel crowns. Given the better bonding of nanocomposites to stainless steel crowns than conventional composites [16], this study aimed to evaluate the bonding of nanocomposites to stainless steel crowns using a universal bonding system.

\section{Materials and Methods}

2.1. Selection of Materials. This study tested the bond strength of commercially available nanocomposite resins to pretrimmed, precontoured posterior stainless steel crowns, (3M, St. Paul, MN, USA) using a new universal bonding system Scotchbon (Universal Adhesive, 3M ESPE, Seefeld, Germany). The bond strength obtained was compared to that of using two currently available dentin bonding agents Adaper Single Bond Plus (3M ESPE, Seefeld Germany) and Prime \& Bond NT (Dentsply, Lichtenstein).

To avoid any chance of incompatibility of the bonding agent with the composite, each bonding agent was tested with a resin manufactured by the same manufacturer (ZX350, 3M ESPE; Ceram-X mono, Dentsply).

2.2. Power of the Sample. The power of the sample was calculated using the G-Power 3.1.3 power analysis software (Universtät Kiel, Germany). The minimum required sample for the one-way ANOVA and post-hoc test, with alpha of 0.05 , was 20 samples in each group. Thus a total of 80 stainless steel crowns were divided into four groups for the purpose of this study.

2.3. Preparation of the Stainless Steel Crowns. The lingual surfaces of 80 pretrimmed, precontoured lower right primary secondary molar crowns (size E5) (3M, St Paul) were sandblasted for 20 seconds using a sandblasting machine to increase retention (Protempomatic Z, Bego, Bremen, Germany). Then the crowns were etched with $37 \%$ phosphoric acid (FineEtch 37, Spident Co. Ltd., Korea) for 15 seconds and divided into four groups of 20 SSCs each. In Group A SSCs were attached to a nanocomposite (ZX350, 3M-ESPE) without the use of a bonding agent (control group). In Group B SSCs were bonded to a nanocomposite (ZX350, 3M-ESPE) using the universal bonding system (Scotchbond Universal Adhesive, 3M ESPE). In Groups C and D SSCs were bonded to nanocomposites using bonding agents from their respective manufacturers (Adaper Single Bond Plus to ZX350, 3M ESPE, and Prime \& Bond NT to Ceram-X Dentsply). After that all SSCs were subjected to thermocycling (500 cycles of thermocycling between $5^{\circ} \mathrm{C}$ and $55^{\circ} \mathrm{C}$ ) to simulate thermal changes in the oral cavity using the technique.

2.4. Measurement of Bond Strength. In order to facilitate handling of the samples the crowns were embedded in a uniform acrylic mold that exposed the lingual surface of each crown to be ready for testing (Figure 1). Then the shear bond

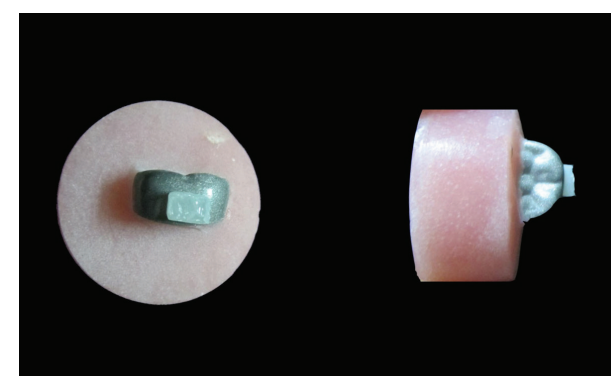

FIGURE 1: Stainless steel crown bonded to composite, mounted in an acrylic resin template.

strength of the composite to the stainless steel crown was measured using a universal testing machine (Instron Corp, Canton, MA, USA). A force of $10 \mathrm{~N}$ at an acceleration of $0.5 \mathrm{~mm} / \mathrm{min}$ was applied upon the crown-composite interface in a direction parallel to the long axis of the crown. All strength readings were calculated in megapascals $(\mathrm{MPa})$ and the force at which the bond fractured was recorded as the shear bond strength of the adhesive.

2.5. Types of Failure. After the fracture of the bond between the composite and the stainless steel crown, the crown samples were examined under a magnifying loupe and a dark background to determine type of failure (Figure 2). Three distinct types of failure were recorded: (a) adhesive failure was recorded when the bond failure was observed at the resin-stainless steel crown interface, (b) cohesive failure was recorded when the bond failure was observed within the resin and (c) mixed failure when the bond failure was located at the resin stainless steel crown as well as within the resin [15].

2.6. Statistical Analyses. All data was recorded and processed using the SPSS ver.20 (IBM Inc., Armonk, NY, USA) data processing software. The one-way ANOVA was used to compare the significance of difference in shear bond strengths between the different groups. Intergroup variations were further illustrated using Scheffe's post-hoc test. Pearson's Chi Square was used to determine the significance of difference among the types of failure.

\section{Results}

Table 1 shows the mean, standard deviations and coefficients of variance of the shear bond strengths of the different groups tested and subjected to the one-way ANOVA. The control group (without any bonding agent) had significantly lower shear bond strength to composite than the groups that utilized bonding agents. The one-way ANOVA showed that this difference was significant at $P<0.0001$. Posthoc Scheffe's test (Table 2) suggested that the shear bond strength of Group B (Scotchbond Universal Adhesive) was significantly higher than that of both Group C (Prime \& Bond NT) and Group D (Adaper Single bond Plus). No significant differences were found between the shear bond strengths of Group C and Group D $(P=.897)$. 
TABLE 1: Descriptive data of the shear bond strengths of the different groups.

\begin{tabular}{|c|c|c|c|c|c|c|}
\hline Group & $N$ & Mean & Std. Deviation & Std. Error & $F$ & Sig $^{*}$ \\
\hline Spectrum + Prime \& Bond NT (D) & 20 & 9.7700 & 5.40089 & 1.20768 & \multirow{4}{*}{32.887} & \multirow{4}{*}{$0.000^{* *}$} \\
\hline Z350XT + Adaper (C) & 20 & 10.7460 & 5.09795 & 1.13994 & & \\
\hline Z350XT + Universal (B) & 20 & 17.6200 & 4.21568 & .94265 & & \\
\hline Control (A) & 20 & 3.7950 & 2.26053 & .50547 & & \\
\hline
\end{tabular}

${ }^{*}$ Calculated using one-way ANOVA.

${ }^{* *}$ Differences significant at $P<0.001$.

TABLE 2: Tukey's HSD post-hoc test to highlight significant differences between the different groups.

\begin{tabular}{lcrc}
\hline Group & $N$ & \multicolumn{2}{c}{ Subset for alpha $=0.05$} \\
& & 1 & 2 \\
\hline Control (A) & 20 & 3.7950 & 9.7700 \\
Spectrum + Prime \& Bond NT (D) & 20 & & 10.7460 \\
Z350XT + Adaper (C) & 20 & & .897 \\
Z350XT + Universal (B) & 20 & 1.000 & 17.6200 \\
Sig. & & 1.000 \\
\hline
\end{tabular}

Means for groups in homogeneous subsets are displayed.

a. Uses harmonic mean sample size $=20.000$.

When the failure type of bonding was compared, the control group showed only adhesive failure, while groups $\mathrm{C}$ and $\mathrm{D}$ showed both adhesive and mixed failures. Although the universal bonding agent group (Group B) showed two samples with pure cohesive failure, this group had an equal number of adhesive and mixed failures (Table 3 ). The type of failure observed in this group was however significantly different from those observed in other groups.

\section{Discussion}

Full coverage restorations are often the only viable means of restoring badly decayed primary teeth [17-19]. Pediatric dentists have recognized the need for an esthetic alternative to stainless steel crowns for anterior teeth [17], and similarly posterior teeth too; parental demand for esthetics has forced pediatric dentists to look at more esthetic options such as preveneered or open-faced crowns [19].

Although parent satisfaction has been reported with preveneered stainless steel crowns [20], drawbacks such as difficulties in shade matching [17], tendencies for the veneered surfaces to fracture [9], limited ability to crimp the crown [21], and fears over long-term clinical performance [22] have prevented their universal acceptance by dentists. A higher rate of clinical success has been reported with open-faced stainless steel crowns although their esthetic acceptability has been questioned [23].

While initial studies on the bonding of composite to stainless steel crowns predicted acceptable shear bond strengths $[12,24,25]$, it has been found that mechanical modifications improve the bond strength $[26,27]$. Sandblasting was chosen as the method to improve retention of the composite to the crown as the equipment is available in most labs and since it is less time consuming and easier to standardize when compared to methods such as welding of orthodontic brackets or creation of grooves manually with a bur [26].

The shear bond strength obtained with the single bottle adhesives were in the range obtained by previous studies using similar adhesives $[16,27]$. The lack of any significant difference between manufacturers seems to validate the initial hypothesis and confirm the need to test newer bonding systems. The results showed that the universal bonding system showed a significantly higher shear bond strength and lower incidence of adhesive failure than both single bottle adhesives indicating that there could be potential for clinical applications of this system in bonding composite to stainless steel.

The bonding failure type has been used as a measure of the success of the bond of adhesive restorations to stainless steel crowns [16, 27]. Adhesive failures have been considered unacceptable, mixed failures acceptable, and cohesive failures ideal [15]. While studies have reported adhesive and mixed failures in the bonding of composite to stainless steel crowns there have been few reports of cohesive failure [15]. In this context, the significantly fewer adhesive failures and finding of cohesive failure in the group that bonded with the universal bonding agent are of significance. However it must be noted that even the group that bonded with universal bonding agent showed incidence of adhesive failure, suggesting that clinical trials of this material are needed to validate the findings of this study.

Because of the relative novelty of the universal bonding agent, there is little available literature on the mechanism of action of this agent. A recent study suggested using selfetching adhesives that utilize 10-methacryloyloxydecyl dihydrogen phosphate (MDP) form self-assembled nanolayers at the tooth-bond interface, which could be the reason for their higher bond strengths to tooth [15]. However both the presence of this layer and the feasibility of this explanation 
TABLE 3: Types of failure observed.

\begin{tabular}{lccccc}
\hline \multicolumn{1}{c}{ Group } & Adhesive & $\begin{array}{c}\text { Type of failure } \\
\text { Cohesive }\end{array}$ & Mixed & Chi Square & Sig \\
\hline Spectrum + Prime \& Bond NT & 16 & 0 & 4 & & \\
Z350XT + Adaper & 14 & 0 & 6 & 9.254 & $0.004^{*}$ \\
Z350XT + Universal & 9 & 2 & 9 & & \\
Control & 20 & 0 & 0 & & \\
\hline
\end{tabular}

${ }^{*}$ Differences significant at $P<0.01$.

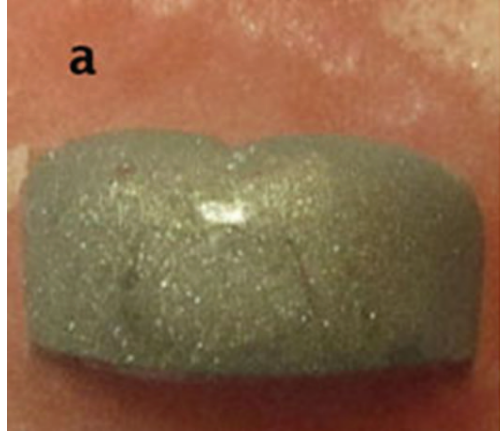

(a)

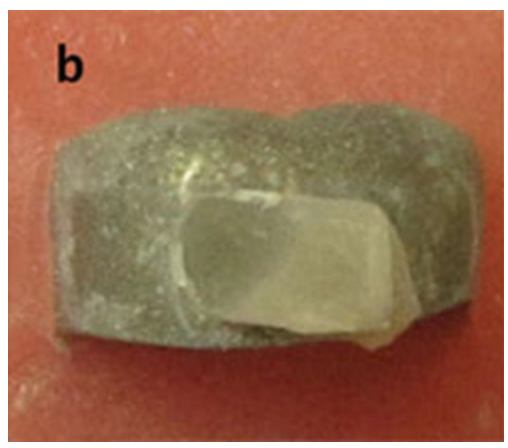

(b)

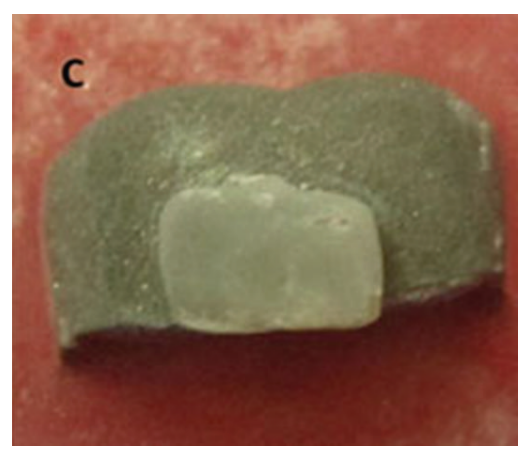

(c)

FIGURE 2: Types of failure of shear bond strength: (a) adhesive failure, (b) mixed failure, and (c) cohesive failure.

with regards to metal bonding need further evaluation. This study used only the universal bonding agent since none of the other commercially available MDP systems claim increased bonding to metal.

The fracture of the veneering of pre-veneered stainless steel crowns has been reported to result in loss of space and retention of plaque $[28,29]$. The repair of the fractured veneer has been reported to be unsuccessful, mainly because of the lack of adequate bonding to the metal surface [28]. The results of this study suggest that the higher bond strengths of universal bonding agent could indicate the need to study their possible use in the repair of fractured veneers of esthetic stainless steel crowns.

\section{Conclusions}

Composites that bonded to stainless steel crowns with the new universal bonding agent show significantly greater shear bond strengths and fewer adhesive failures when compared to traditional single bottle systems. Further clinical research is needed to evaluate the in vivo potential of this system.

\section{Conflict of Interests}

The authors confirm that no financial assistance was received from the manufacturers of any of the products used in the study. The authors have never been employed or served as consultants for the manufacturers of any of the products mentioned in this study.

\section{References}

[1] A. F. Mata and R. D. Bebermeyer, "Stainless steel crowns versus amalgams in the primary dentition and decision-making in clinical practice," General Dentistry, vol. 54, no. 5, pp. 347-350, 2006.

[2] N. J. Levering and L. B. Messer, "The durability of primary molar restorations: III. Costs associated with placement and replacement," Pediatric Dentistry, vol. 10, no. 2, pp. 86-93, 1988.

[3] J. F. Roberts and M. Sherriff, "The fate and survival of amalgam and preformed crown molar restorations placed in a specialist paediatric dental practice," British Dental Journal, vol. 169, no. 8, pp. 237-244, 1990.

[4] A. Lucchese, A. Bertacci, S. Chersoni, and M. Portelli, "Primary enamel permeability: a SEM evaluation in vivo," European Journal of Paediatric Dentistry, vol. 13, pp. 231-235, 2012.

[5] AAPD, "American Academy of Pediatric Dentistry reference manual 2011-2012," Pediatric Dentistry, vol. 33, pp. 1-349, 2011.

[6] S. Beattie, B. Taskonak, J. Jones et al., "Fracture resistance of 3 types of primary esthetic stainless steel crowns," Journal of the Canadian Dental Association, vol. 77, article b90, 2011.

[7] A. B. Fuks, D. Ram, and E. Eidelman, "Clinical performance of esthetic posterior crowns in primary molars: a pilot study," Pediatric Dentistry, vol. 21, no. 7, pp. 445-448, 1999.

[8] W. F. Waggoner and H. Cohen, "Failure strength of four veneered primary stainless steel crowns," Pediatric Dentistry, vol. 17, no. 1, pp. 36-40, 1995.

[9] D. Ram, A. B. Fuks, and E. Eidelman, "Long-term clinical performance of esthetic primary molar crowns," Pediatric Dentistry, vol. 25, no. 6, pp. 582-584, 2003.

[10] C. Roberts, J. Y. Lee, and J. T. Wright, "Clinical evaluation of and parental satisfaction with resin-faced stainless steel crowns," Pediatric Dentistry, vol. 23, no. 1, pp. 28-31, 2001. 
[11] Y. Yilmaz, T. Gurbuz, O. Eyuboglu, and N. Belduz, "The repair of preveneered posterior stainless steel crowns," Pediatric Dentistry, vol. 30, no. 5, pp. 429-435, 2008.

[12] K. R. Wiedenfeld, R. A. Draughn, and J. B. Welford, "An esthetic technique for veneering anterior stainless steel crowns with composite resin," ASDC Journal of Dentistry for Children, vol. 61, no. 5-6, pp. 321-326, 1994.

[13] L. D. Koroluk and G. A. Riekman, "Parental perceptions of the effects of maxillary incisor extractions in children with nursing caries," ASDC Journal of Dentistry for Children, vol. 58, no. 3, pp. 233-236, 1991.

[14] J. Perdigao, A. Sezinando, and P. C. Monteiro, "Laboratory bonding ability of a multi-purpose dentin adhesive," American Journal of Dentistry, vol. 25, pp. 153-158, 2012.

[15] Y. Yoshida, K. Yoshihara, N. Nagaoka et al., "Self-assembled Nano-layering at the adhesive interface," Journal of Dental Research, vol. 91, no. 4, pp. 376-381, 2012.

[16] A. Khatri, B. Nandlal, and Srilatha, "Comparative evaluation of shear bond strength of conventional composite resin and nanocomposite resin to sandblasted primary anterior stainless steel crown," Journal of Indian Society of Pedodontics and Preventive Dentistry, vol. 25, no. 2, pp. 82-85, 2007.

[17] N. Attari and J. F. Roberts, "Restoration of primary teeth with crowns: a systematic review of the literature," European Archives of Paediatric Dentistry, vol. 7, no. 2, pp. 58-63, 2006.

[18] N. S. Chun, "Esthetic primary anterior crowns," Hawaii Dental Journal, vol. 29, no. 2, p. 9, 1998.

[19] M. W. O'Riordan, S. N. Shah, and M. Tremblay, "Full-coverage restorations of primary anterior teeth," The Journal of the Michigan Dental Association, vol. 87, no. 1, pp. 34-70, 2005.

[20] C. Champagne, W. Waggoner, M. Ditmyer, P. S. Casamassimo, and J. MacLean, "Parental satisfaction with preveneered stainless steel crowns for primary anterior teeth," Pediatric Dentistry, vol. 29, no. 6, pp. 465-469, 2007.

[21] M. Gupta, J. W. Chen, and J. C. Ontiveros, "Veneer retention of preveneered primary stainless steel crowns after crimping," Journal of Dentistry for Children, vol. 75, no. 1, pp. 44-47, 2008.

[22] R. Leith and A. C. O'Connell, "A clinical study evaluating success of 2 commercially available preveneered primary molar stainless steel crowns," Pediatric Dentistry, vol. 33, pp. 300-306, 2011.

[23] Y. Yilmaz and M. E. Koçoğullari, "Clinical evaluation of two different methods of stainless steel esthetic crowns," Journal of Dentistry for Children, vol. 71, no. 3, pp. 212-214, 2004.

[24] R. Carrel and R. Tanzilli, "A veneering resin for stainless steel crowns," The Journal of Pedodontics, vol. 14, no. 1, pp. 41-44, 1989.

[25] T. P. Croll and M. L. Helpin, "Preformed resin-veneered stainless steel crowns for restoration of primary incisors," Quintessence International, vol. 27, no. 5, pp. 309-313, 1996.

[26] T. A. al-Shalan, M. J. Till, and R. J. Feigal, "Composite rebonding to stainless steel metal using different bonding agents," Pediatric Dentistry, vol. 19, no. 4, pp. 273-276, 1997.

[27] F. S. Salama and B. F. el-Mallakh, "An in vitro comparison of four surface preparation techniques for veneering a compomer to stainless steel," Pediatric Dentistry, vol. 19, no. 4, pp. 267-272, 1997.

[28] D. Ram and B. Peretz, "Composite crown-form crowns for severely decayed primary molars: a technique for restoring function and esthetics," Journal of Clinical Pediatric Dentistry, vol. 24, no. 4, pp. 257-260, 2000.
[29] P. V. Shah, J. Y. Lee, and J. T. Wright, "Clinical success and parental satisfaction with anterior preveneered primary stainless steel crowns," Pediatric Dentistry, vol. 26, no. 5, pp. 391395, 2004. 


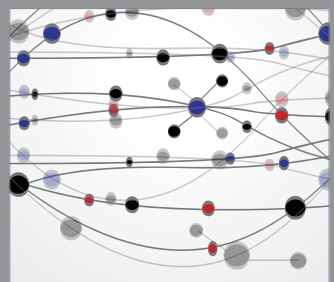

The Scientific World Journal
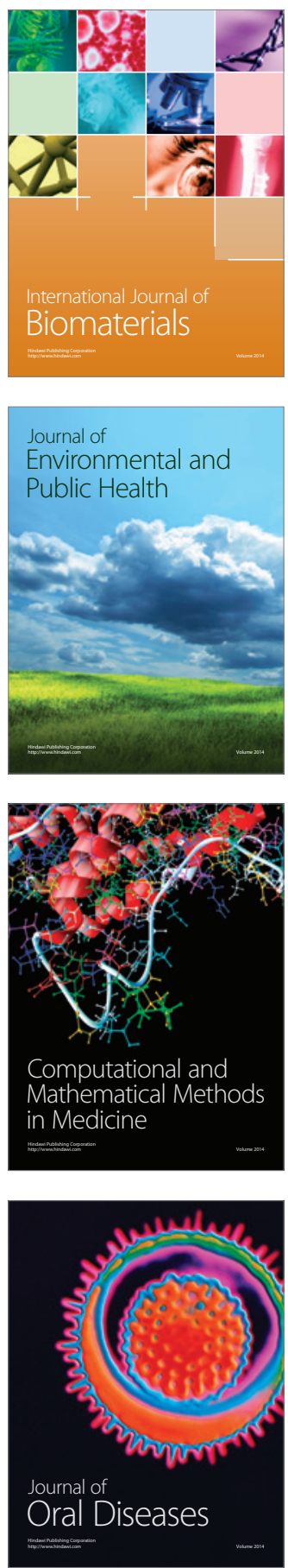
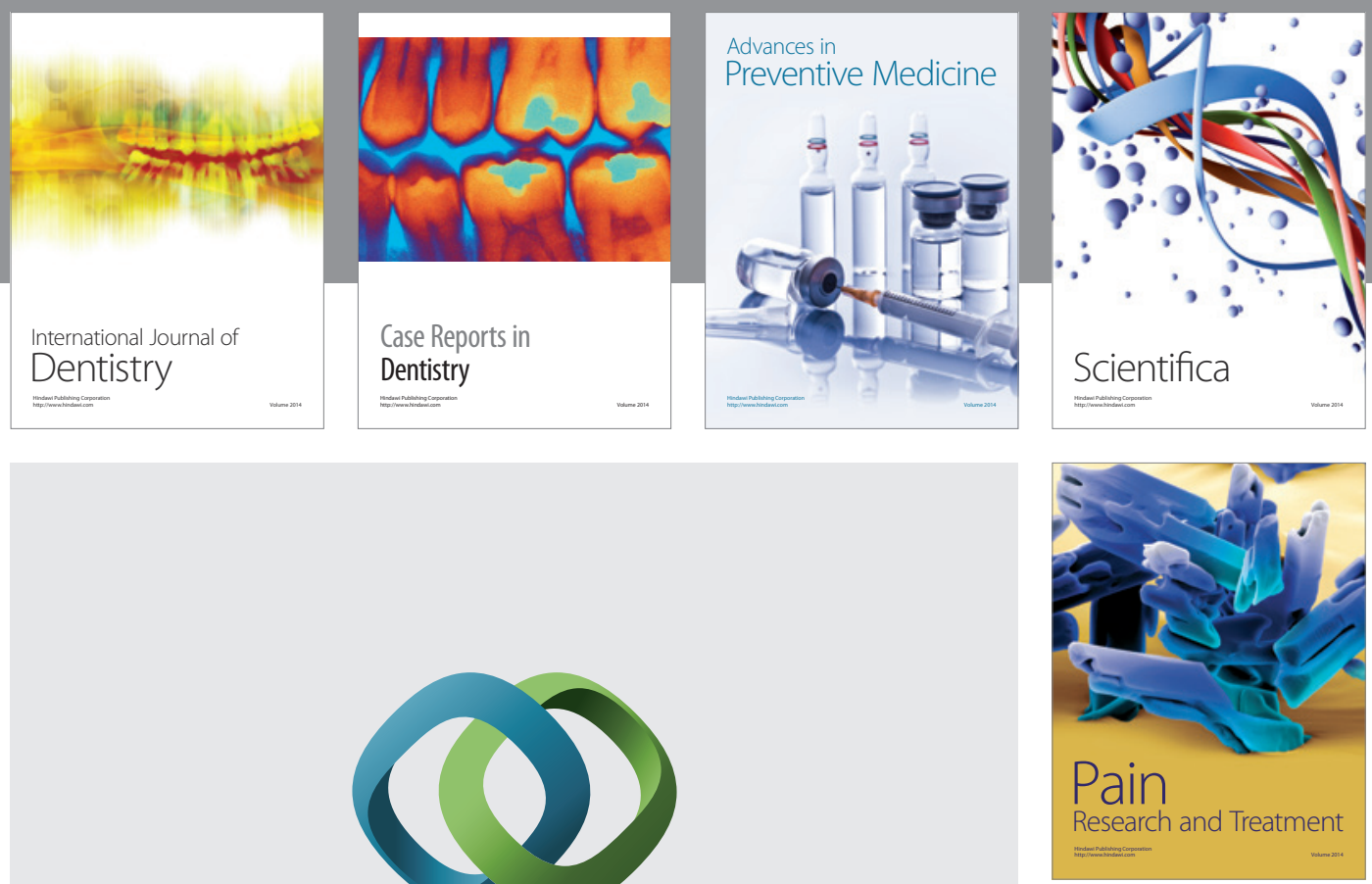

\section{Hindawi}

Submit your manuscripts at

http://www.hindawi.com
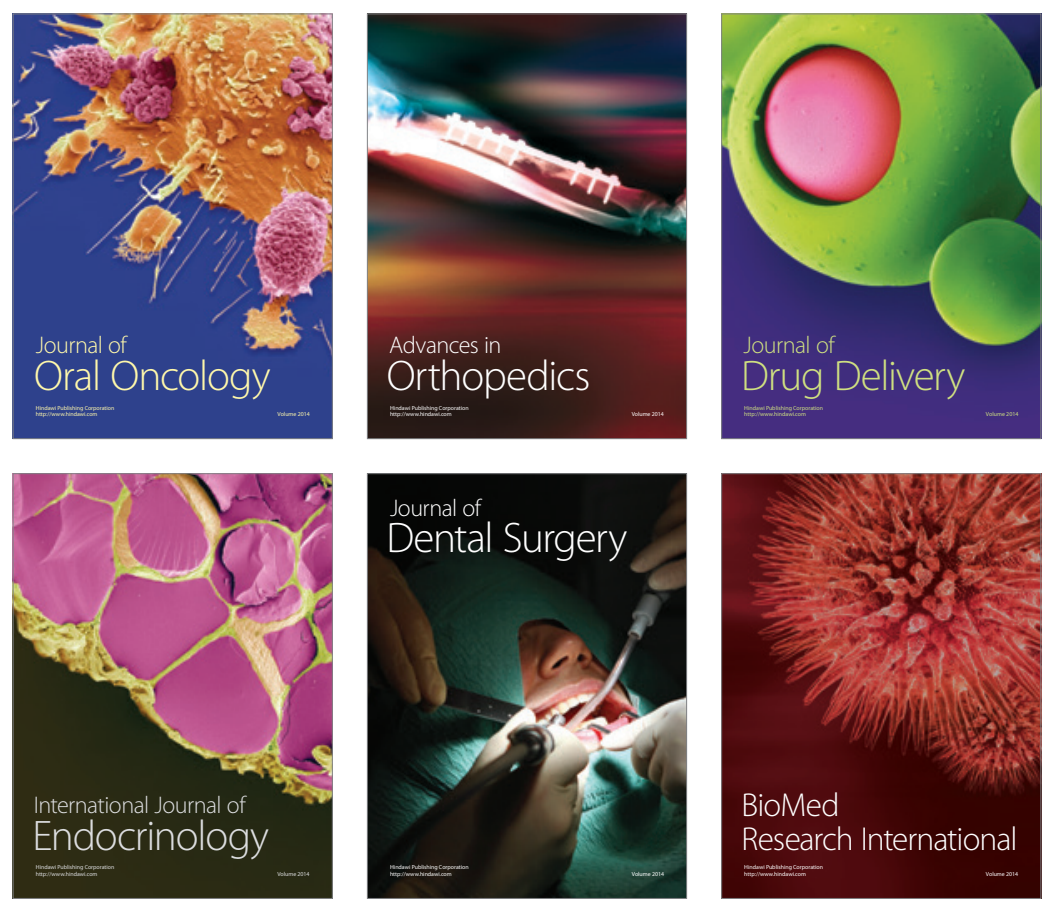

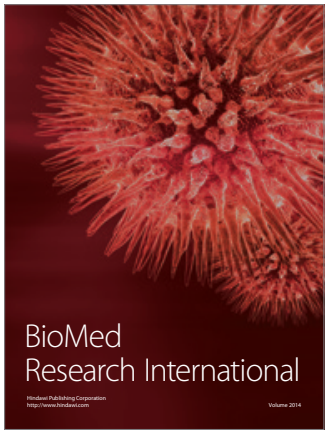

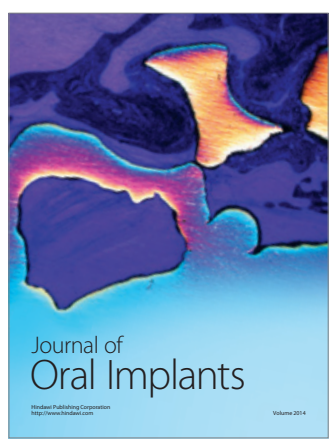
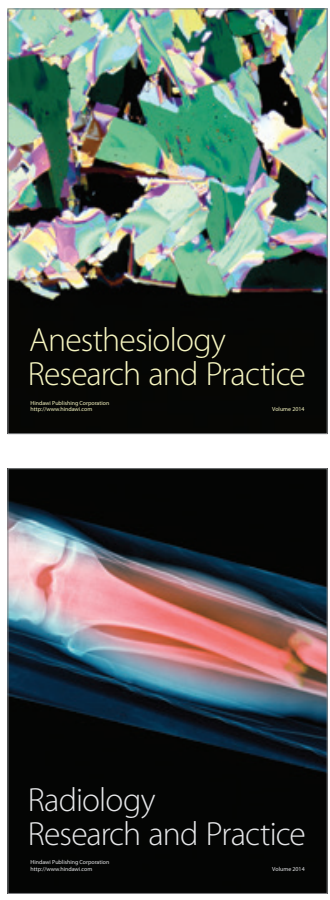